\title{
Protein S deficiency complicated with repetitive peripheral arterial thrombosis successfully treated by mechanical thrombectomy device with Rotarex system
}

\author{
Wei-Sheng Liao ${ }^{1}$, Wei-Tsung $\mathrm{Wu}^{1}$, Nai-Yu Chi ${ }^{1}$, Wen-Hsien Lee ${ }^{1,2,3}$, Chun-Yuan Chu ${ }^{1,2,3}$, Ching-Tang Chang ${ }^{1,3}$, \\ Ho-Ming Su, ${ }^{1,2}$, Tsung-Hsien Lin ${ }^{1,2}$, Po-Chao Hsu¹,2 \\ ${ }^{1}$ Division of Cardiology, Department of Internal Medicine, Kaohsiung Medical University Hospital, Kaohsiung Medical University, \\ Kaohsiung, Taiwan \\ ${ }^{2}$ Department of Internal Medicine, Faculty of Medicine, School of Medicine, Kaohsiung Medical University, Kaohsiung, Taiwan \\ ${ }^{3}$ Graduate Institute of Medicine, School of Medicine, Kaohsiung Medical University, Kaohsiung, Taiwan
}

Received: November 27, 2017

Accepted: December 13, 2017

Online Published: December 18, 2017

DOI: $10.5430 /$ crim.v5n1p5

URL: https://doi.org/10.5430/crim.v5n1p5

\begin{abstract}
Protein S deficiency is an inherited thrombophilia associated with an increased risk of venous thromboembolism. However, arterial thrombosis is a relative rare complication of protein $\mathrm{S}$ deficiency and the prognosis of these patients was worse than those without protein $\mathrm{S}$ deficiency in the literature. Herein we reported a 43-year-old male with protein $\mathrm{S}$ deficiency experiencing several times acute peripheral arterial thrombosis of left leg. Surgical thrombectomy was performed initially but later endovascular treatment (EVT) was suggested. Although EVT was successfully performed by catheter-directed thrombolysis (CDT), arterial thrombosis still recurred three months later. CDT was tried again but thrombosis could not be treated by this strategy anymore. Therefore, we used mechanical thrombectomy device (Rotarex system) and successfully regained the straight-line blood flow to the foot after the procedure. Peripheral echo showed patent flow after 6 months follow-up. In conclusion, arterial thrombosis is a relative rare complication of protein S deficiency and prognosis was not well in the literature, our case reminds physicians that Rotarex system is a safe and highly efficient device for acute PAOD even in the patients with hypercoagulable state.
\end{abstract}

Key Words: Protein S deficiency, Peripheral artery occlusive disease, Catheter directed thrombolysis, Mechanical thrombectomy

\section{INTRODUCTION}

Protein S deficiency is an inherited thrombophilia associated with an increased risk of thromboembolism. Protein $\mathrm{S}$ is a vitamin K-dependent plasma glycoprotein synthesized in the endothelium. It is characterized as an essential role in anticoagulation pathway, which also functioned as a cofactor for activated Protein $\mathrm{C}$ to inactivate of Factor Va and VIIIa in the coagulation cascade. ${ }^{[1,2]}$ The most common clinical manifes- tation of protein S deficiency is venous thromboembolism; however, some studies also showed that protein $\mathrm{S}$ deficiency may be a risk factor for arterial thrombosis formation. ${ }^{[3,4]}$ Herein we reported a 43-year-old male suffering from repetitive peripheral arterial thrombosis was diagnosed as protein S deficiency and finally successfully treated by mechanical thrombectomy device (Rotarex).

*Correspondence: Po-Chao Hsu; Email: pochao.hsu@gmail.com; Address: Division of Cardiology, Department of Internal Medicine, Kaohsiung Medical University Hospital, 100 Tzyou 1st Road, Kaohsiung 80708, Taiwan. 


\section{CASe PResentation}

A 43-year-old male suffered from recurrent intermittent claudication was referred to our cardiovascular (CV) department by $\mathrm{CV}$ surgeon. Tracing back his medical history, he was a case of hypertension and coronary artery disease (Single vessel disease) under regular medical control and denied of tobacco, alcohol, and illicit drug use. He suffered from acute onset of left leg pain five years ago and acute limb ischemia (ALI) was diagnosed at that time. Emergent angiography showed left superficial femoral artery (SFA) total occlusion and surgical thrombectomy was performed. Then he kept surgeon outpatient visit follow-up. However, the similar episode occurred 6 months later and surgical embolectomy was performed again. Due to recurrent acute peripheral arterial thrombosis, serial laboratory examination was performed and protein $\mathrm{S}$ deficiency was diagnosed according to laboratory data at then. Therefore, $\mathrm{CV}$ surgeon prescribed warfarin for long-term anticoagulation use.

Under warfarin use, intermittent claudication got improvement and patient kept outpatient visit for four years. Unfortunately, sudden-onset left leg pain with intermittent claudication happened again, the patient came to surgeon outpatient visit and was arranged admission for further treatment. Ankle-brachial index (ABI) measurement was 0.58 over left leg. Laboratory data showed PT (patient/control): 19.3/10.8 (INR: 1.91). Because patient already had two surgical thrombectomy history and left femoral area already had scar formation. Surgeon referred the patient to our CV department for endovascular treatment (EVT).
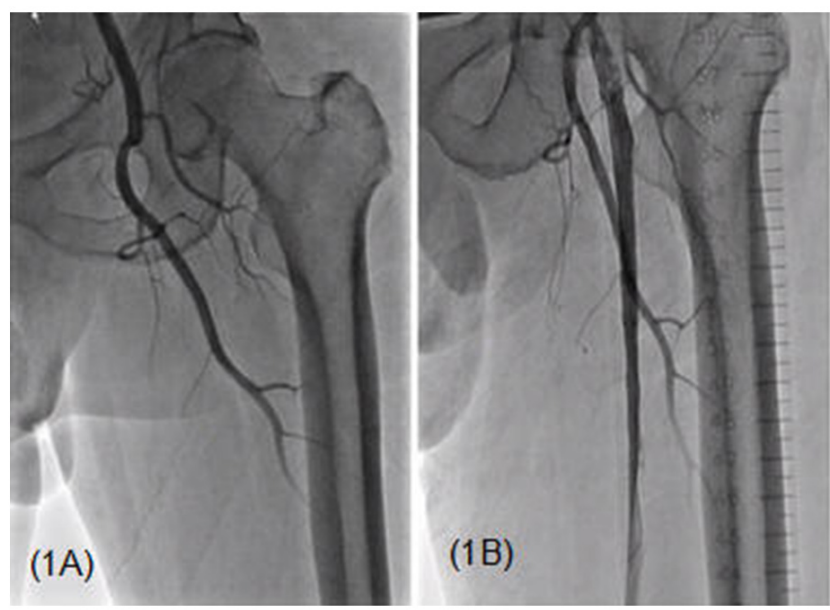

Figure 1. (A) Left leg angiography before 1st endovascular treatment. (B) Final angiography post CDT and stenting for left superficial femoral artery after 1st endovascular treatment.

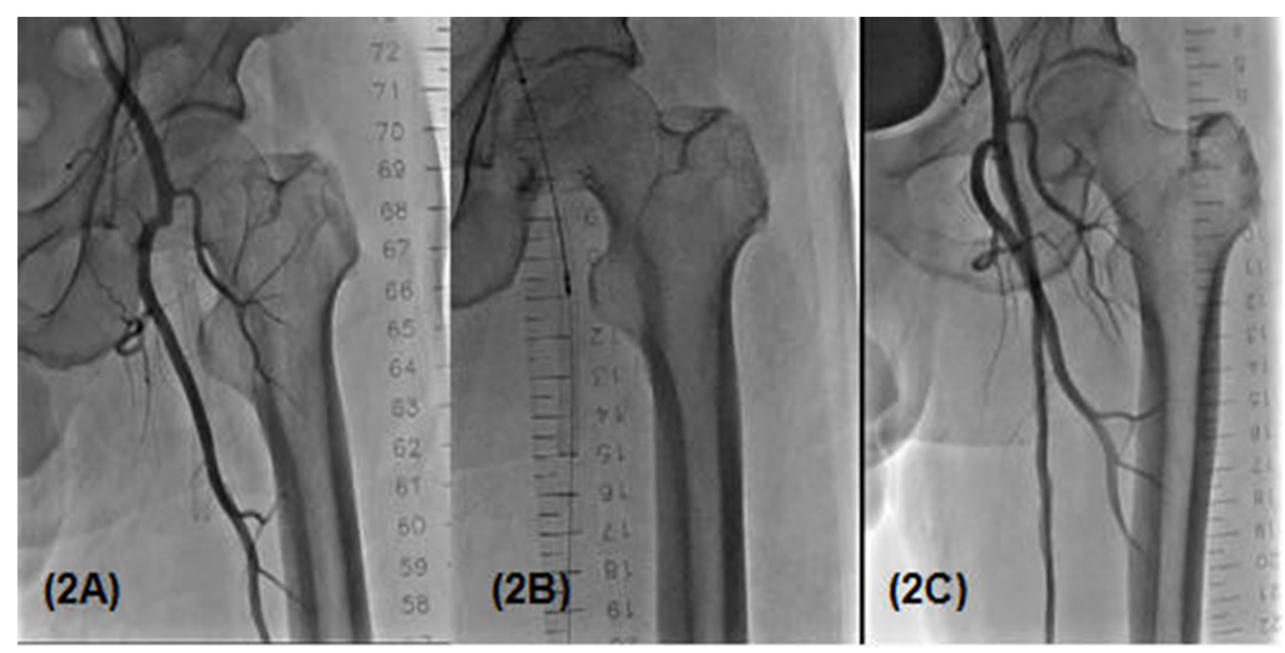

Figure 2. (A) Left leg angiography before second endovascular treatment. (B) Rotarex thrombectomy device use for left superficial femoral artery total occlusion. (C) Final angiography post Rotarex use and further angioplasty.

This time, left leg angiography showed SFA total occlusion with collateral to distal popliteal artery (see Figure 1A). We performed percutaneous transluminal angioplasty (PTA) for left SFA and inserted fountain catheter for catheter-directed thrombolysis (CDT) treatment with urokinase infusion. After CDT for three days, angiography showed improved blood flow and further PTA and stenting with one bare metal stent was done for left SFA (see Figure 1B). We then added back warfarin and titrated dose to keep INR within 2-3. Due to stable condition, the patient was discharged and kept CV outpatient visit follow-up. However, four months later, similar symptom/sign occurred again and ankle-brachial index (ABI) of left leg became unmeasurable. Therefore, patient was admitted for further treatment. This time, angiography 
showed left SFA total occlusion again (see Figure 2A). We performed CDT with urokinase infusion for 3 days but it failed to resolve the SFA thrombosis. Because mechanical thrombectomy device of Rotarex system (Straub Medical AG, Switzerland) just entered Taiwan, so we decided to apply Rotarex system to perform thrombectomy. This was the first case using Rotarex system in Taiwan and after the first attempt, we successfully remove the most of thrombus from SFA and follow-up angiography showed improved blood flow to distal vessels. Then we performed Rotarex device again and further angioplasty for the lesions (see Figure 2B). Final angiography revealed great SFA blood flow after the procedure (see Figure 2C). Follow-up ABI was 1.04 with great improvement. Then the patient was discharged uneventfully and kept regular anti-coagulation therapy at our out-patient visit. We performed peripheral ultrasound examination 6 months later and result showed biphasic flow and persistent patency over left SFA (see Figure 3).

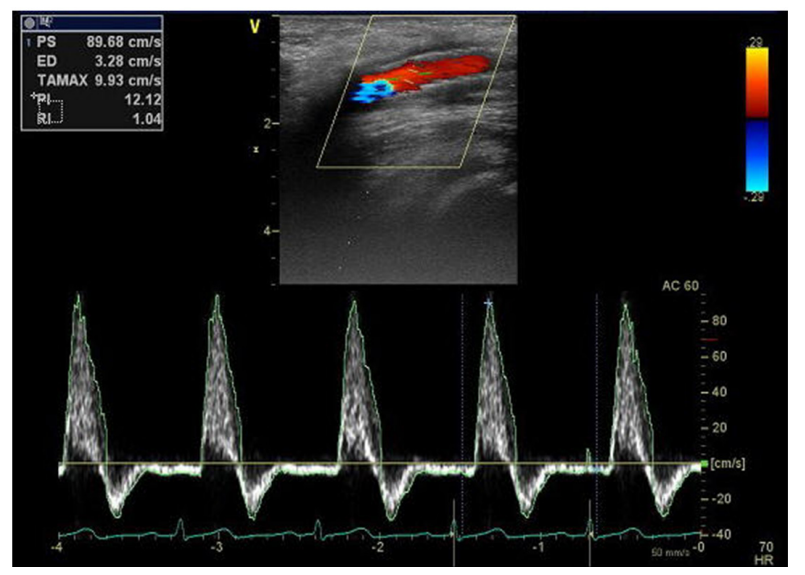

Figure 3. Peripheral ultrasound examination 6 months later showed biphasic flow and persistent patency over left superficial femoral artery

\section{Discussion}

Peripheral arterial occlusive disease (PAOD) is a systemic atherosclerotic process, and the major risk factors of PAOD are similar to those of coronary artery disease and cerebral vascular disease. ${ }^{[5]}$ These risk factors include hypertension, diabetes mellitus, dyslipidemia, an advanced age, cigarette smoking, and so on. ${ }^{[5,6]}$ ALI is related to a sudden decrease in arterial perfusion in the limb and most of the causes are due to thrombosis and embolism. Hypercoagulable state is one of the potential cause of thrombosis which may lead to ALI. Protein C/S deficiency is an inherited thrombophilia associated with an increased risk of thromboembolism. However, the inherited hypercoagulable syndromes such as protein $\mathrm{S}$ deficiency primarily affect veins and only rarely cause arterial thrombosis. There were only limited case reports dis- cussing about the association between protein $\mathrm{S}$ deficiency and peripheral arterial thrombosisof lower extremities. ${ }^{[7,8]}$ Horowitz et al. reported a boy with inherited protein $\mathrm{S}$ deficiency suffered from progressive painful discoloration of the lower extremities and was treated with transfusion and anticoagulation, but still finally leaded to toe amputation. ${ }^{[7]}$ Archer et al. also reported a 42-year-old woman with protein $\mathrm{S}$ deficiency had acute occlusion of dorsal pedis artery. Despite attempts to restore distal perfusion, the patient still eventually required below-the-knee amputation. ${ }^{[8]}$ In addition, Thongboon et al. studied thrombophilia profile in Thai patients with arterial thrombotic disorders including stroke and peripheral arteries and found significant association of low protein $\mathrm{S}$ with poor outcome. ${ }^{[3]}$ Komai et al. also found that PAOD patients with reduced anti-coagulation proteins showed worse prognosis than those without. ${ }^{[4]}$

In our case, the patient suffered from several times peripheral arterial thrombosis episode. Although initial treatment of surgical thrombectomy was success, surgeon did not favor repetitive surgical thrombectomy due to scar formation over left femoral area and referred the patient to our department for endovascular treatment. CDT treatment by urokinase infusion was initially useful in this case, however, it still failed in the second attempt. The cause of CDT failure might be related to subacute or organized thrombus which was difficult to be treated by thrombolysis.

The Rotarex system is one of the advanced mechanical thrombectomy device, which combines mechanical clot fragmentation and removal of the fragmented material from the vessel under negative pressure to prevent peripheral embolization. It has been recognized as an efficient and safe method to treat acute, subacute or even chronic occlusions or stenosis of peripheral vessels. ${ }^{[9-14]}$ In addition, the company of Rotarex system also has another device - Aspirex which is created for thrombus aspiration for venous system such as deep venous thrombosis. ${ }^{[15]}$ Due to venous valve issue, generally Rotarex system can not be used in venous system for thrombus aspiration. According to Heller S's study, Rotarex system as a first-line mini-invasive treatment in infrainguinal ALI is safe, quick, and effective, and the performance outcomes can be superior to that of traditional surgical embolectomy. ${ }^{[13]}$ Although our patient was a case of protein $\mathrm{S}$ deficiency with repetitive arterial thrombosis episode and previous thrombolysis failure, we still finally regained excellent blood flow by Rotarex thrombectomy device.

\section{Conclusion}

Peripheral arterial thrombosis of lower extremities is a rare but possible complication of protein $\mathrm{S}$ deficiency and the 
prognosis of these patients was worse than those without deficiency. Our case reminds physicians that despite failure of CDT treatment, mechanical thrombectomy device such as Rotarex system is a highly efficient and safe device for acute
PAOD even in the patients with hypercoagulable state.

\section{CONFLiCTS OF InTEREST Disclosure}

The authors have declared no conflicts of interest.

\section{REFERENCES}

[1] Koppelman S, Hackeng T, Sixma J, et al. Inhibition of the intrinsic factor $\mathrm{X}$ activating complex by protein $\mathrm{S}$ : evidence for a specific binding of protein S to factor VIII. Blood. 1995; 86: 1062-71. PMid:7620160

[2] Hackeng TM, Van't Veer C, Meijers J, et al. Human protein S inhibits prothrombinase complex activity on endothelial cells and platelets via direct interactions with factors Va and Xa. J Biol Chem 1994; 269: 21051-8. PMid:8063724

[3] Thongboon A, Rojnuckarin P, Akkawat B, et al. Thrombophilia profile in Thai patients with arterial thrombotic disorders. J Med Assoc Thai. 2006 Sep; 89 Suppl 3: S150-4. PMid:17718281

[4] Komai H, Juri M. Impact of reduced endogenous anti-coagulation protein activity on vascular events of peripheral arterial disease. Int Angiol. 2009 Apr; 28(2): 138-43. https://doi .org/10.1016/j. jvs. 2009.02.077

[5] Bartholomew JR, Olin JW. Pathophysiology of peripheral arterial disease and risk factors for its development. Cleve Clin J Med. 2006; 73 Suppl 4: S8-14. PMid:17385386 https ://doi .org/10.3949/ ccjm.73.Suppl_4.S8

[6] Selvin E, Erlinger TP. Prevalence of and risk factors for peripheral arterial disease in the United States: results from the National Health and Nutrition Examination Survey, 1999-2000. Circulation. 2004 110: 738-43. PMid:15262830 https://doi.org/10.1161/01.C IR. 0000137913.26087 . FO

[7] Horowitz IN, Galvis AG, Gomperts ED. Arterial thrombosis and protein S deficiency. J Pediatr. 1992 Dec; 121(6): 934-7. https: //doi.org/10.1016/S0022-3476(05) 80346-4

[8] Archer KA, Lembo T Jr, Haber JA. Protein S deficiency and lowerextremity arterial thrombosis: complicating a common presenta- tion. J Am Podiatr Med Assoc. 2007 Mar-Apr; 97(2): 151-5. PMid:17369323 https://doi.org/10.7547/0970151

[9] Stanek F, Ouhrabkova R, Prochazka D. Mechanical thrombectomy using the Rotarex catheter-safe and effective method in the treatment of peripheral arterial thromboembolic occlusions. Vasa. 2010; 39: 334-40. PMid:21104623 https://doi.org/10.1024/0301 $-1526 / \mathrm{a} 000058$

[10] Horsch A, van Oostayen J, Zeebregts C, et al. The Rotarex ${ }^{\circledR}$ and Aspirex ${ }^{\circledR}$ mechanical thrombectomy devices. Surg Technol Int 2009; 18: 185-92. PMid:19579204

[11] Vorwerk D. Mechanical thrombectomy in acute and subacute leg ischemia. Acta Chir Belg. 2003; 103: 548-54. PMid:14743557

[12] Freitas B, Steiner S, Bausback Y, et al. Rotarex Mechanical Debulking in Acute and Subacute Arterial Lesions: Single-Center Experience with 525 Patients. Angiology. 2017 Mar; 68(3): 233-41. PMid:27194755 https://doi.org/10.1177/00033197166466 82

[13] Heller S, Lubanda JC, Varejka P, et al. Percutaneous Mechanical Thrombectomy Using Rotarex ${ }^{\circledR}$ S Device in Acute Limb Ischemia in Infrainguinal Occlusions. Biomed Res Int. 2017; 2017: 2362769. PMid:28555191 https://doi.org/10.1155/2017/2362769

[14] Kronlage M, Printz I, Vogel B, et al. A comparative study on endovascular treatment of (sub)acute critical limb ischemia: mechanical thrombectomy vs thrombolysis. Drug Des Devel Ther. 2017 Apr 18; 11: 1233-41. PMid:28458517 https://doi .org/10.2147/DDDT .S131503

[15] Horsch AD, van Oostayen J, Zeebregts CJ, et al. The Rotarex ${ }^{\circledR}$ and Aspirex ${ }^{\circledR}$ mechanical thrombectomy devices. Surg Technol Int. 2009 Apr; 18: 185-92. PMid:19579204 